Chapter 17

\title{
Moisture-Dependent Engineering Properties of Chia (Salvia hispanica L.) Seeds
}

\author{
Estefanía N. Guiotto, Vanesa Y. Ixtaina, \\ Mabel C. Tomás and Susana M. Nolasco \\ Additional information is available at the end of the chapter \\ http://dx.doi.org/10.5772/53173
}

\section{Introduction}

Salvia hispanica L., whose common name is chia, is an annual herbaceous plant belonging to the Lamiaceae or Labiatae family. This botanical species, native to southern Mexico and northern Guatemala, was an important crop in pre-Columbian Mesoamerica in conjunction with corn, beans and amaranth. Chia seeds were valuated not only for food, but also for medicines and paints [1]. Its cultivation was banned by Spanish conquerors and replaced by exotic crops (wheat and barley) [2]. Nowadays, chia seeds are being reintroduced to western diets in order to improve human health.

These seeds have been investigated and recommended due to their oil content with the highest proportion of $\alpha$-linolenic acid (omega-3) compared to other natural source known to date $[3,4]$, and also because of their high levels of protein, antioxidant, dietary fiber, vitamins and minerals $[5,6]$. Chia seeds from Argentina exhibited $30.0-38.6 \mathrm{~g}$ oil/100 g, with 60.7 - $67.8 \mathrm{~g} / 100 \mathrm{~g}$ of $\alpha$-linolenic acid [7, 8]. Figure 1 shows the chemical composition of chia seed [9].

Chia seed is traditionally consumed in Mexico, the southwestern U.S., and South America, but it is not widely known in Europe. However, in 2009, the European Union approved chia seeds as a novel food, allowing them to comprise up to $5 \%$ of a bread product's total matter [10]. Today, chia is mostly grown in Mexico, Bolivia, Argentina, Ecuador, Australia, and Guatemala, and it has been demonstrated that the species has great potential as a future crop plant $[7,11]$. 


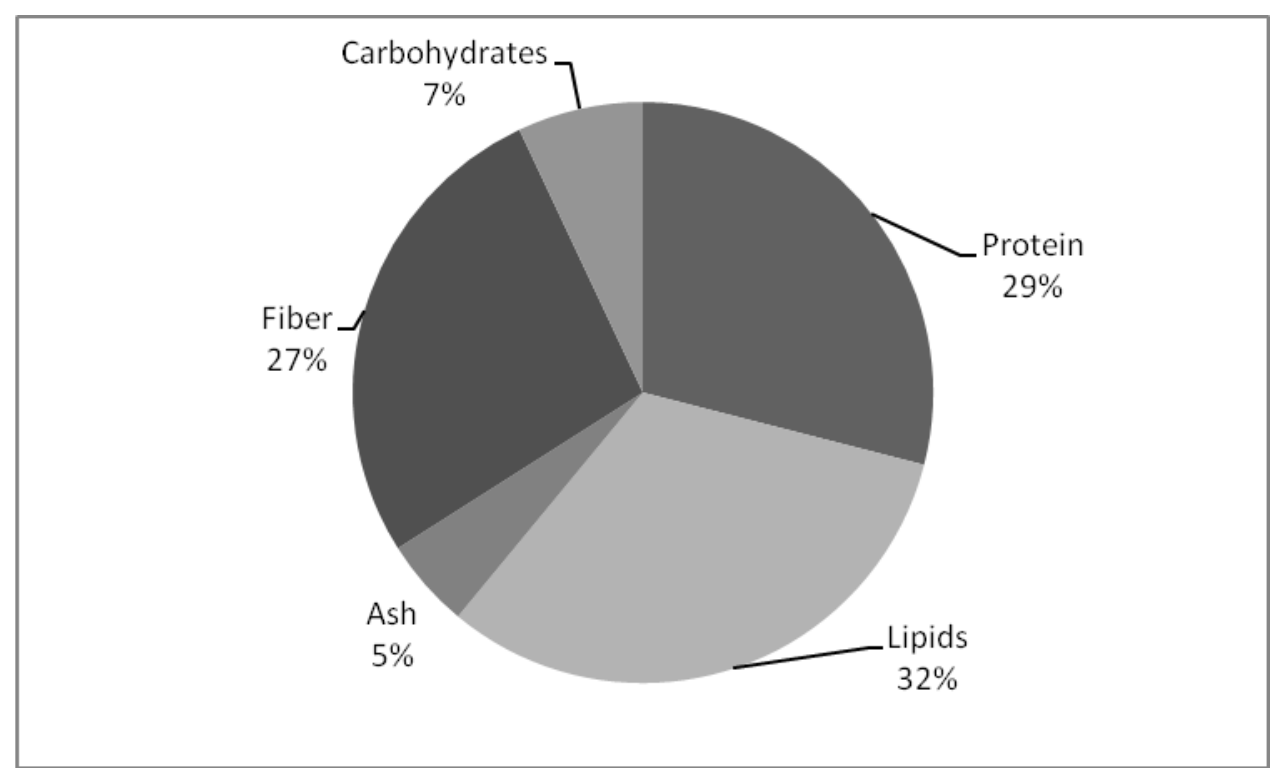

Figure 1. Chemical composition of chia seed (\% d.b.)

Salvia hispanica fruit consist in four nutlets, similar to an indehiscent achene, which contains a single seed. These nutlets, are commercially named as seeds, and in the text, we will use this last term. The plant produces small white and dark seeds. Most of chia population that is commercially grown today contains a low percentage of white seeds. Their shapes are oval and in general, the white seeds are somewhat larger than the black ones. Ixtaina et al. [12], reported length, width and thickness value of 2.11, 1.32 and $0.81 \mathrm{~mm}$ for dark seeds and $2.15,1.40$ and $0.83 \mathrm{~mm}$ for white seeds, respectively. Chia seeds are shown in Figure 2.

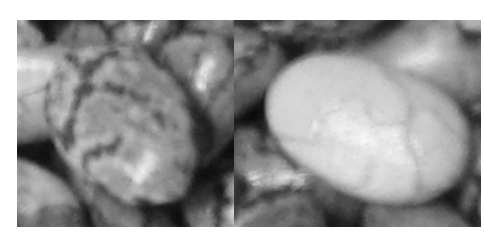

Figure 2. Photographs of dark and white chia seeds (13x)

The knowledge of engineering properties constitutes important and essential data for the design of machines, storage structures, and processes. The value of this basic information is not only important to engineers but also to food scientists, processors, and other scientists who may exploit these properties and find new uses. 
Engineering seed properties and their dependence on moisture content are necessary in the design of equipment for transporting, storage and/or processing. The knowledge of the morphology and size distribution of chia seeds is essential for the adequate design of the equipment for cleaning, grading and separation. Gravimetric properties are useful for the design of equipment related to aeration, drying, storage and transport. Bulk density determines the capacity of storage and transport systems while true density is useful for separation equipment; porosity of the mass of seeds determines the resistance to airflow during the aeration and drying of seeds. The frictional properties, such as the angle of repose and the static coefficient of friction, are important for the design of grain bins and other storage structures whose operation is influenced by the compressibility and flow behaviour of materials. Several researchers investigated the moisture dependence of engineering properties of seed or grain and reported different behaviour of these properties as a function moisture content.

The aim of this work was to evaluate the engineering properties of dark chia seed as a function of the moisture content and to compare their behavior with that of other grains.

\section{Materials and methods}

\subsection{Seeds}

Chia seeds $(20 \mathrm{~kg})$ were obtained from commercial sources in Salta, Argentina $\left(25^{\circ} \mathrm{S}, 65.5^{\circ}\right.$ W). Seeds were packed in hermetic plastic vessels and stored at $5 \pm 1^{\circ} \mathrm{C}$ until use. The seeds were manually cleaned to remove all foreign matter, such as stones, dirt, and broken seeds. In this way, a randomized sample of chia seeds (about $2 \mathrm{~kg}$ ) was picked by a sample splitter (CPASA, Centro Proveedor Agropecuario, Buenos Aires, Argentina). The seeds were manually separated according to their white or dark pericarp surface.

\subsection{Sample preparation}

The dark chia seeds were further divided into seven lots and they were conditioned to obtain a moisture content range of 4.6 - 17.7\% (d.b.).To obtained a less moisture content, a predetermined quantity of seeds was dried down to the desired moisture content (convection air oven, $40-45^{\circ} \mathrm{C}$ ). Higher moisture contents were reached indirectly through the saturation of the atmosphere in contact with the seeds. For this purpose, small, clean and dry vessels containing the seeds were placed into a container with $100 \mathrm{~cm}^{3}$ of water, which was then hermetically sealed for $36-240 \mathrm{~h}$. These moisture levels were selected according to the conditions usually applied in harvesting and most processing operations of grains [13].

\subsection{Moisture content}

The moisture content of the samples was determined by the ASAE standard method used for rapeseed [14], using a convection air oven at $130 \pm 1^{\circ} \mathrm{C}$ for $4 \mathrm{~h}$. 


\subsection{Engineering properties}

The engineering properties of seeds were assessed at all moisture levels, as described below.

In order to determine the average size of the seeds, a sample of 100 seeds was randomly selected. For each individual seed, the three principal dimensions, namely length $(L)$, width $(W)$ and thickness $(T)$, were measured using a digital micrometer (least count $0.01 \mathrm{~mm}$ ). The three principal dimensions were used to calculate the geometric mean diameter $\left(D_{\mathrm{g}}\right)$ and surface area $(S)$ of individual grains by assuming that the seeds were ellipsoid.

The geometric mean diameter $\left(D_{g}\right)$ of chia seeds was calculated using the following relationship [15]:

$$
D_{g}=(L W T)^{1 / 3}
$$

The specific surface area $(S)$ of chia seeds was calculated it according to equation 2 [16]:

$$
S=\pi D_{g}^{2}
$$

To determine the mass of a thousand seeds $\left(W_{1000}\right)$, a set of 100 randomly selected seeds was weighed with an analytical balance (0.0001 g accuracy) and then extrapolated to 1000 seeds. This process was replicated 30 times [13].

The bulk density $\left(\rho_{b}\right)$, considered as the ratio of the mass sample of the seeds to its total volume, was determinate using a weight per hectoliter tester [16] (equipment of $90 \mathrm{~cm}^{3}$ of total volume). The true density $\left(\rho_{t}\right)$ defined as the ratio of the mass of the sample to its true volume, was determined using an electronic balance reading $0.001 \mathrm{~g}$ and a pycnometer $(50 \pm 0.1$ $\mathrm{cm}^{3}$ capacity, liquid displacement method)[17]. The toluene $\left(\mathrm{C}_{7} \mathrm{H}_{8} ; \rho=0.867 \mathrm{~g} \mathrm{~cm}^{-3}\right)$ was used as a solvent to prevent water absorption in the seeds during the experiment [16]. Both measurements were performed in triplicate.

The porosity value $(\varepsilon)$ defined as the fraction of space in the bulk seed which is not occupied by the seed [18], was determined from bulk and true densities using the relationship given by [19] and [20] as follows:

$$
\varepsilon=\left(\frac{\left(\rho_{t}-\rho_{b}\right)}{\rho_{t}}\right) \times 100
$$

The seed volume $(V)$ was determined from the following relationship [21] 


$$
V=\left(\frac{m}{\rho_{t}}\right) 10^{3}
$$

where $m$ is the unit mass of the seed $(\mathrm{g})$ determined in samples used to calculate the true density.

The equivalent diameter $\left(D_{e}\right)$ and sphericity $(\phi)$, defined as the ratio between the surface area of the sphere having the same volume as that of the seed and the surface area of the seed, were calculated using equation 5 and equation 6 respectively [18]:

$$
\begin{aligned}
& D_{e}=\left(\frac{6 V}{\pi}\right)^{1 / 3} \\
& \phi=\left(\frac{D_{e}}{L}\right) \times 100
\end{aligned}
$$

\begin{tabular}{lll}
\hline \multicolumn{1}{c}{ Seed } & Moisture Content (\%d.b.)* & \multicolumn{1}{c}{ Reference } \\
\hline Cumin & $7.0-22.0$ & Singh and Goswami, 1996. [13] \\
\hline Sunflower & $4.0-20.0$ & Gupta and Das, 1997. [15] \\
\hline Fenugreek & $8.9-20.1$ & Altuntaş et al., 2005. [16] \\
\hline Safflower & $3.7-15.6$ & Baümler et al., 2006. [17] \\
\hline Sunflower & $2.0-18.8$ & de Figueiredo et al., 2006 [18] \\
\hline Sunflower & $2.9-20.1$ & de Figueiredo et al., 2006 [18] \\
\hline Quinoa & $4.6-25.8$ & Vilche et al., 2003. [22] \\
\hline Soybean & $8.7-25.0$ & Deshpande et al., 1993. [23] \\
\hline Amaranth & $7.7-43.9$ & Abalone et al., 2004. [24] \\
\hline Chia & $4.6-17.7$ & Guiotto et al., 2011 [25] \\
\hline Cotton & $8.3-13.8$ & Özarslan, 2002. [26] \\
\hline Flaxseed & $6.1-16.2$ & Coşkuner and Karababa, 2007 [27] \\
\hline Rapeseed & $4.7-24.0$ & Çalişir et al., 2005. [28] \\
\hline * Moisture content range considered in each study & \\
\hline
\end{tabular}

Table 1. References studying the engineering properties of several seeds

The static coefficient of friction was measured using two structural materials, namely galvanized iron and aluminum. These materials are commonly used for transport, storage, 
and handling operations of grains, pulses, and seed and for building storage and drying bins. A PVC cylinder (50 $\mathrm{mm}$ diameter, $50 \mathrm{~mm}$ high, open at both ends) was placed on an adjustable tilting table, faced with the test surface, and filled with the sample. The structural surface with the cylinder resting on it was tilted gradually with a screw device until the cylinder just started to slide down [22]. The angle $(\alpha)$ was read on a graduated scale and the friction coefficient was calculated using the following relationship:

$$
\mu=\tan \alpha
$$

where $\mu$ is the static coefficient of friction, and $\alpha$ is the angle of tilt (degrees). The static coefficient of friction was replicated reading ten times for each moisture content.

Different authors evaluated the engineering properties of several seeds as a function of seed moisture content (Table 1). These data were considered to compare the behavior of different grain properties with regard to moisture content.

\section{Results and discussion}

Dark seeds represented $89 \%$ by mass of the samples studied. The initial moisture content was $10.0 \%$ and $10.9 \%$ d.b., for dark and white seeds, respectively. Averages of the three principal dimensions were $L=1.97 \mathrm{~mm}, W=1.29 \mathrm{~mm}$, and $T=0.84 \mathrm{~mm}$ for dark chia seeds. The statistical analysis (ANOVA) detected significant differences $(p \leq 0.05)$ between different moisture levels for each principal dimension. Figure 3, shows a linearly increasing tendency between the dimensions $(L, W$, and $T)$ and moisture content $\left(R^{2}>0.95, p \leq 0.005\right)$. Similar trends of increase have been reported in fenugreek [16], quinoa [22], soybean [23] and amaranth [24] seeds. Knowledge of the seed axial dimensions is important, for instance, in determining aperture sizes in the design of grain handling machinery.

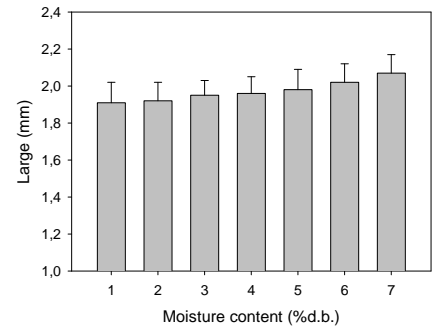

(a)

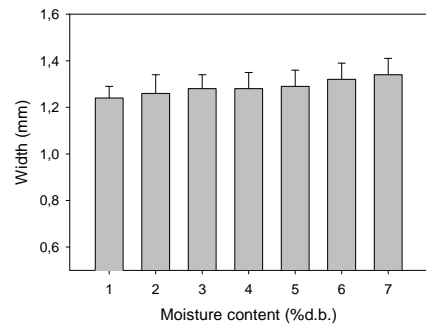

(b)

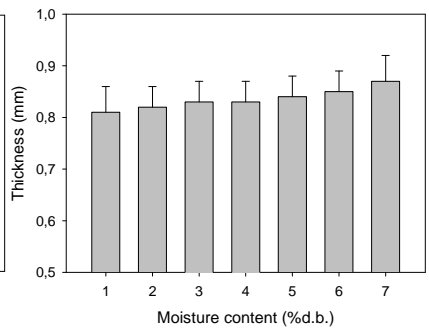

(c)

Figure 3. Principal dimensions (a) length $(L)$; (b) width $(W)$; (c) thickness $(T)$ of dark chia seeds with different moisture content (1) $4.6 \%$, (2) $6.5 \%$, (3) $8.7 \%$, (4) $10.0 \%$, (5) $12.5 \%$, (6) $15.3 \%$, (7) $17.7 \%$ ).

The geometric mean of the axial dimensions is useful in estimating the projected area of a particle moving in the turbulent or near-turbulent region of an air stream. It is therefore gen- 
erally indicative of its pattern of behavior in air streams, especially with respect to the ease of separating extraneous materials from the particle during cleaning by pneumatic means [26]. Significant differences $(p<0.05)$ were found between different moisture contents for geometric diameter $\left(D_{g}\right.$, mean $\left.1.28 \mathrm{~mm}\right)$ and for specific area $\left(S\right.$, mean $\left.5.20 \mathrm{~mm}^{2}\right)$. Both properties, $D_{g}$ and $S$, increased linearly $8.14 \%$ and $16.9 \%$, respectively, in function of increasing moisture content $\left(\mathrm{R}^{2}>0.97, p<0.005\right)$ (Table 2 and Figure 4$)$. This $D_{g}$ trend was similar to that observed for amaranth, flaxseed, quinoa and soybean. Similar behavior of $S$ was reported for fenugreek and soybean seeds. The increase of $S$ may be due to seed dilatation during moisture sorption, resulting in contact area enhancement.

\begin{tabular}{lll}
\hline Seed [Reference] & Regression equation & $\mathbf{R}^{2}$ \\
\hline Amaranth [24] & $1.071+0.00385 x$ & 0.99 \\
\hline Chia [25] & $1.2075+0.0057$ & 0.97 \\
\hline Flaxseed [27] & $1.941+0.011 x$ & 0.97 \\
\hline Quinoa [22] & $1.359+0.009819 x$ & 0.99 \\
\hline Soybean [23] & $4.882+0.0253 x$ & 0.99 \\
\hline
\end{tabular}

Table 2. Regression equation as a function of moisture content ( $x, \%$ d.b.) with their respective coefficient of determination $\left(\mathrm{R}^{2}\right)$ for geometric diameter $\left(\mathrm{D}_{\mathrm{g}} \mathrm{mm}\right)$.

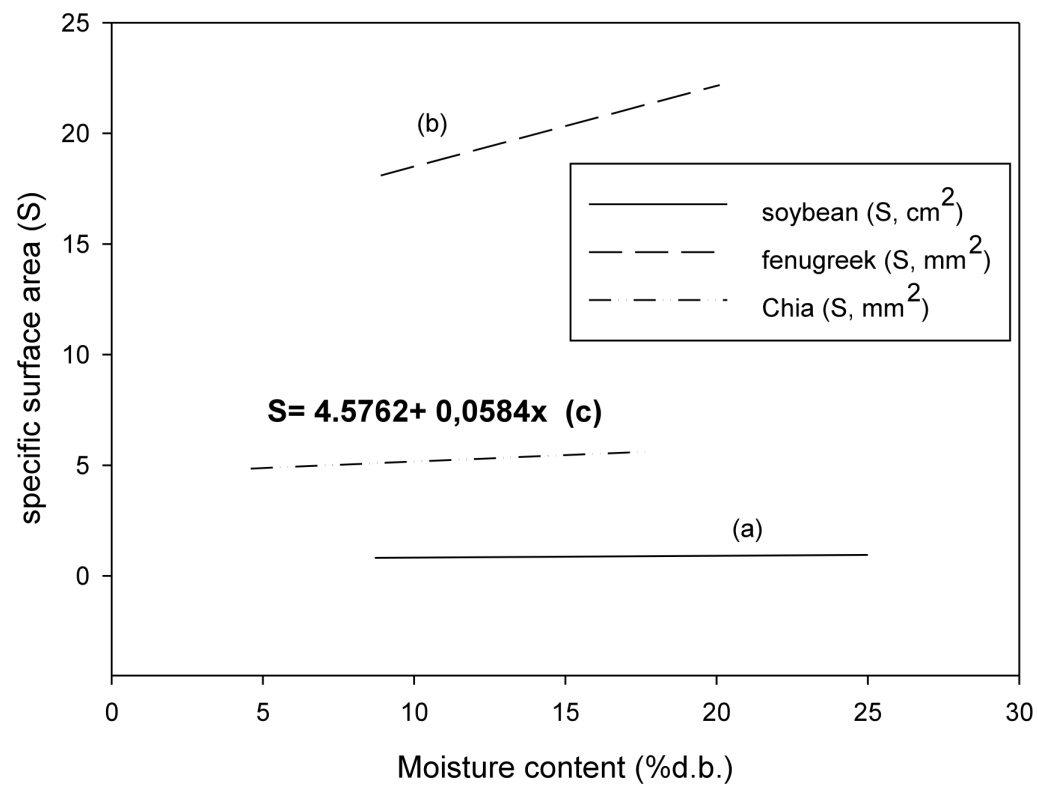

Figure 4. Effect of moisture content ( $x, \%$ d.b.) on specific area $(S)$. Date correspond to the adjusted function reported by (a) [23]; (b) [16] and (c) [25] 
Bulk density, true density, and porosity (the ratio of inter granular space to the total space occupied by the grain) can be useful in sizing grain hoppers and storage facilities; they can affect the rate of heat and mass transfer of moisture during aeration and drying processes. The theories used to predict the structural loads for storage structures have bulk density as basic parameter. Bulk density and porosity are major considerations in designing near-ambient drying and aeration systems, as these properties affect the resistance to airflow of the stored mass. Grain bed with low porosity will have greater resistance to water vapor scape during the drying process, which may lead to higher power to drive the aeration fans.

True density average of dark chia seeds with different moisture content was $1.069 \mathrm{~g} \mathrm{~cm}^{-3}$. Statistical analysis showed significant differences $(p \leq 0.05)$ between different moisture levels. The true density of seed was found to increase linearly at a decreasing in moisture content from 4.6 to $17.7 \%$ d.b. The relationship between true density $\left(\rho_{t}, \mathrm{~g} \mathrm{~cm}^{-3}\right)$ and the moisture content ( $\mathrm{x}, \%$ d.b.) of the seed can be represented for $\rho_{t}=1.1457-0.008 \mathrm{x}\left(\mathrm{R}^{2}=0.9912\right.$, $p<0.0001$ ) [25]. This trend can be attributed to minor volumetric product contraction during drying with respect to the decrease of seed mass due to water loss. The negative linear relationship of true density with moisture content was also observed by other authors for fenugreek and soybean, but it was different for cumin, flaxseed, quinoa and sunflower seeds, which increased linearly. However, a non-linear decreasing relationship of true density with moisture content was reported for amaranth and safflower seed (Table 3).

\begin{tabular}{lll}
\hline Seed [Reference] & Regression equation & $\mathbf{R}^{2}$ \\
\hline Cumin [13] & $1010+6.05 \times$ & 0.98 \\
\hline Flaxseed [27] & $826.92+28.91 \times$ & 0.99 \\
\hline Fenugreek [16] & $1275.8-37.555 \times$ & 0.99 \\
\hline Quinoa [22] & $853.19+13.16 x$ & 0.98 \\
\hline Sunflower [15] & $694.6+3.72 \times$ & 0.92 \\
\hline Sunflower* [18] & $706.12+4.06 x$ & 0.94 \\
\hline Soybean [23] & $1254.8-5.258 \times$ & 0.99 \\
\hline Amaranth [24] & $\begin{array}{l}(1411(100+x)) / \\
(100+1,25 x)\end{array}$ \\
\hline Safflower [17] & $\begin{array}{l}0,7887+(0,000298 x)- \\
(0,0004551 \times 2)\end{array}$ \\
\hline * black-hull oilseed & 0.99 \\
\hline
\end{tabular}

Table 3. Regression equations as a function of moisture content ( $x, \%$ d.b.) with their respective coefficient of determination $\left(R^{2}\right)$ for true density $\left(\rho_{t}, \mathrm{~kg} \mathrm{~m}^{-3}\right)$. 
Chia seed bulk density decreased from 0.713 to $0.644 \mathrm{~g} \mathrm{~cm}^{-3}$ as a function of the increase of moisture content. Table 4 shows the relationship of bulk density with moisture content reported by different authors for several seeds. Regarding bulk density, chia seeds presented a behavior similar (non-linear) to those of cumin and safflower seeds. The negative linear relationship of bulk density with moisture content was observed by other authors for amaranth, flaxseed, fenugreek, quinoa, rapeseed, sunflower and soybean (Table 4). The decrease in bulk density of seed with increase in moisture content indicates that the increase in volumetric expansion is greater than weight.

\begin{tabular}{lcl}
\hline Seed [Reference] & Regression equation & $\mathbf{R}^{2}$ \\
\hline Amaranth [24] & $869-3.50 \times$ & 0.87 \\
\hline Chia [25] & $697.7+5.0 \times-0.4 x^{2}$ & 0.99 \\
\hline Cumin [13] & $407+15.67 \times-0.70 x^{2}$ & 0.97 \\
\hline Flaxseed [27] & $822.43-15.308 \times$ & 0.99 \\
\hline Fenugreek [16] & $726.76-27.675 \times$ & 0.98 \\
\hline Quinoa [22] & $771.5-3.94 \times$ & 0.98 \\
\hline Rapeseed [28] & $616.74-1.4518 \times$ & 0.93 \\
\hline Safflower [17] & $452.2-0.12 x^{2}$ & 0.96 \\
\hline Sunflower [15] & $472.4-1.69 \times$ & 0.88 \\
\hline Sunflower* [18] & $446.35-201 \times$ & 0.87 \\
\hline Sunflower** [18] & $528,75-2.24 \times$ & 0.80 \\
\hline Soybean [23] & $748.9-1.6626 \times$ & 0.99 \\
\hline * black-hull oilseed, **striped-hull oilseed & \\
\hline
\end{tabular}

Table 4. Regression equations as a function of moisture content ( $x, \%$ d.b.) with their respective coefficient of determination $\left(R^{2}\right)$ for bulk density $\left(\rho_{b}, \mathrm{~kg} \mathrm{~m}^{-3}\right)$.

These discrepancies observed for as much true density as for bulk density could be due to cell structure and the volume and mass increase characteristics of the seeds as moisture content increases [29].

The average porosity observed for all dark samples was $35.3 \%$, with significant differences $(p \leq 0.05)$ among moisture contents. The polynomial relationship between the porosity $(\varepsilon, \%)$ and moisture content ( $\mathrm{x}, \%$ d.b.) for chia seeds can be represented by $\varepsilon=40.0745-1.0991 \mathrm{x}+$ $\left.0.0049 \mathrm{x}^{2}\right)\left(\mathrm{R}^{2}=0.9701, p<0.0010\right)$ [25]. Nevertheless, different authors reported linear increase in porosity with increase in moisture content for amaranth, cumin, flaxseed, fenugreek, quinoa, rapeseed, safflower, sunflower seeds, and trend linear decrease in porosity for soybean (Table 5). 


\begin{tabular}{lcl}
\hline Seed [Reference] & Regression equation & $\mathbf{R}^{\mathbf{2}}$ \\
\hline Amaranth [24] & $28+0.16 \times$ & 0.75 \\
\hline Cumin [13] & $48+0.643 \times$ & 0.93 \\
\hline Flaxseed [27] & $11.453+2.7621 \times$ & 0.99 \\
\hline Fenugreek [16] & $42.987+0.555 \times$ & 0.95 \\
\hline Quinoa [22] & $13.1+1.22 \times$ & 0.98 \\
\hline Rapeseed [28] & $44.659+0.6656 \times$ & 0.99 \\
\hline Safflower [17] & $39.53+0.342 \times$ & 0.93 \\
\hline Sunflower [15] & $32.27+0.54$ & 0.95 \\
\hline Sunflower* [18] & $36.99+0.58 \times$ & 0.92 \\
\hline Sunflower** [18] & $30.10+0.37 \times$ & 0.91 \\
\hline Soybean [23] & $40.5-0.1365 \times$ & 0.98 \\
\hline * black-hull oilseed, **striped-hull oilseed & \\
\hline
\end{tabular}

Table 5. Regression equations as a function of moisture content ( $x, \%$ d.b.) with their respective coefficient of determination $\left(R^{2}\right)$ for porosity $(\varepsilon, \%)$.

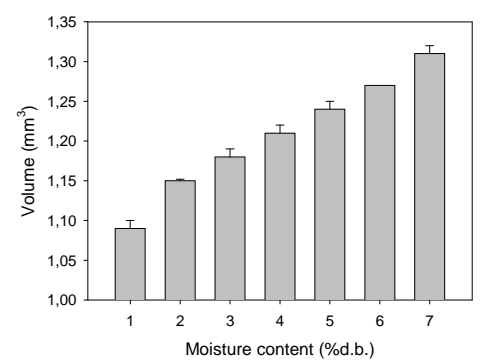

(a)

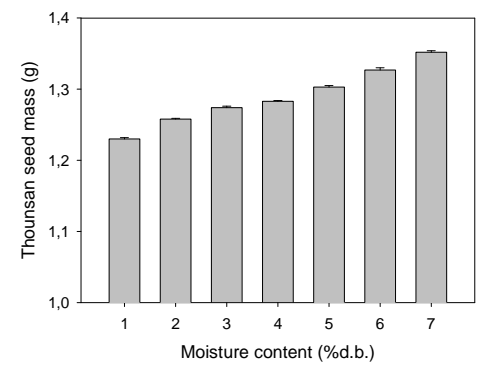

(c)

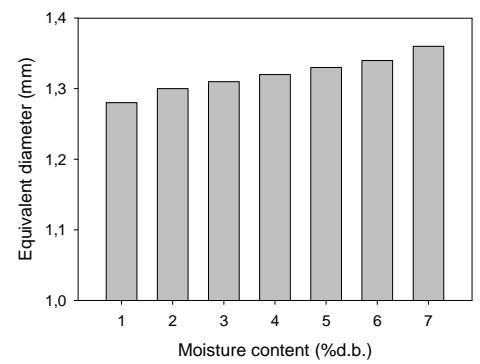

(b)

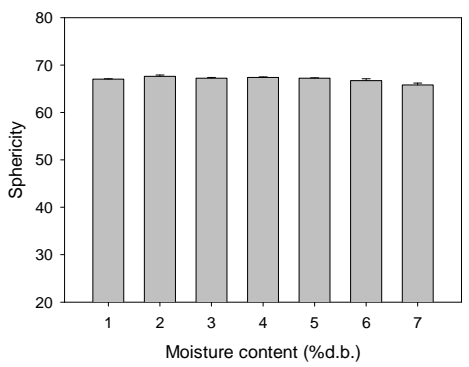

(d)

Figure 5. (a) volume $(V)$, (b) equivalent diameter $(D e),(c)$ thousand seed mass $\left(W_{1000}\right)$, and (d) sphericity ( ) of dark chia seeds with different moisture content (1) $4.6 \%$, (2) $6.5 \%$, (3) $8.7 \%$, (4) $10.0 \%$, (5) $12.5 \%$, (6) $15.3 \%$, (7) $17.7 \%$ ). 
Since porosity depends on bulk and true densities, the magnitude of its variation depends mainly on these properties. Therefore, the porosity of each type of seed or grain could respond differently with increasing moisture content. This fact could be attributed to the seeds' morphological characteristics; the relative changes in their length, width, and thickness; and the associated bulk and true densities. Taking into account the high level of polyunsaturated fatty acids, chia seeds can be easily affected by temperature. For this reason, aeration is an important process to maintain a low uniform temperature and prevent the moisture migration. The resistance to airflow or pressure drop is affected by different factors, such as the bulk density, porosity, and moisture content. Due to the low bulk density and size of chia seeds, the grain bed will have an important pressure drop, requiring a high level of power for driving the aeration fans [25].

The variation of volume $(V)$, equivalent diameter $\left(D_{e}\right)$, thousand seed mass $\left(W_{1000}\right)$, and sphericity $(\phi)$ of chia seeds with moisture content (4.6 - 17.7\% d.b.) is shown in Figure 5.; the average values were $1.21 \mathrm{~mm}^{3}, 1.32 \mathrm{~mm}, 0.129 \mathrm{~g}$ and $66.7 \%$ respectively. Statistical analysis revealed significant differences $(p<0.05)$ between seeds with different moisture content for $V, D_{e}$ and $W_{1000}$. Nevertheless, sphericity did not present significant differences $(p>0.05)$.

The sphericity varied between $65.8 \%$ and $67.6 \%$, values higher than the data reported for sunflower and safflower seed, but lower than those of amaranth, quinoa, rapeseed and soybean seed (Table 6).

\begin{tabular}{lc}
\hline Seed [Reference] & Sphericity (\%) \\
\hline Amaranth [24] & $82 \#$ \\
\hline Fenugreek[16] & $60.79-64.06$ \\
\hline Quinoa [22] & $77-80$ \\
\hline Rapeseed [28] & $93-92$ \\
\hline Safflower [17] & $58-62$ \\
\hline Sunflower* [18] & $49-52$ \\
\hline Sunflower** [18] & $47-50$ \\
\hline Soybean [23] & $80.6-81.6$ \\
\hline \# mean value, * black-hull oilseed, ** striped-hull \\
oilseed
\end{tabular}

Table 6. Sphericity $(\phi)$ of different seeds

The high $\phi$ value thus suggests that the seeds tend towards a spherical shape. Thus, the value of the $\phi$ generally indicates a likely difficulty in getting the seed to roll. This tendency to either roll or slide should be necessary in the design of hoppers and dehulling equipment for the seed. 
As can be seen in Figure 6, the equivalent diameter $\left(D_{e}, \mathrm{~mm}\right)$ increased linearly from 1.28 to $1.36 \mathrm{~mm}$ when the moisture content was increased from $4.6 \%$ d.b. to $17.7 \%$ d.b., representing a variation of $6.3 \%$.

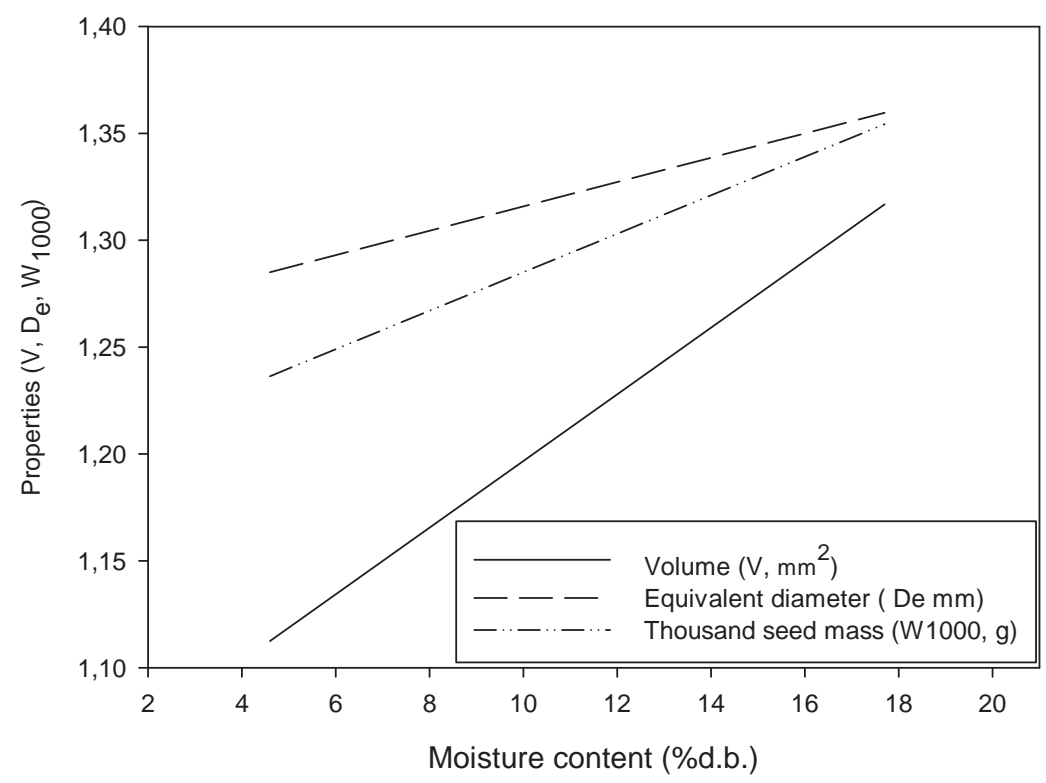

Figure 6. Effect of moisture content ( $x, \%$ d.b.) on volume seed $(V)$, equivalent diameter $\left(D_{\mathrm{e}}\right)$ and thousand seed mass $\left(W_{1000}\right)$. Date corresponds to the adjusted function reported by [25].

The $V$ and $W_{1000}$ of dark chia seeds linearly increased with moisture content (Figure 6). The similar trend was reported for fenugreek [16], safflower [17] sunflower [18] soybean [23] and rapeseed [28] seeds.

The frictional characteristics are important for the proper design of agricultural product handling equipment. Friction between a seed and a surface has an influence on the movement of particles on oscillating conveyors, separation on oscillating sieves and unloading and loading operations. The static coefficient of friction of dark chia seeds was determined on two structural surfaces: galvanized iron and aluminum. The values obtained were higher for aluminum (mean: 0.30, minimum: 0.26, maximum: 0.37) than for galvanized iron (mean: 0.28, minimum: 0.25 , maximum: 0.34 ). Increments of $28.4 \%$ and $29.5 \%$ were recorded for the galvanized iron and aluminum surfaces, respectively, as the moisture content increased from $4.6 \%$ to $17.7 \%$ d.b. The reason for the increased friction coefficient at higher moisture content may be that the water present in the seed offered a cohesive force on the contact surface and the seed became rougher and sliding characteristics are diminished [22, 26]. For both structural surfaces, the co- 
efficient of static friction increased linearly with an increase in moisture content. Similar trends were reported for cumin, flaxseed, quinoa and sunflower (Figure 7).

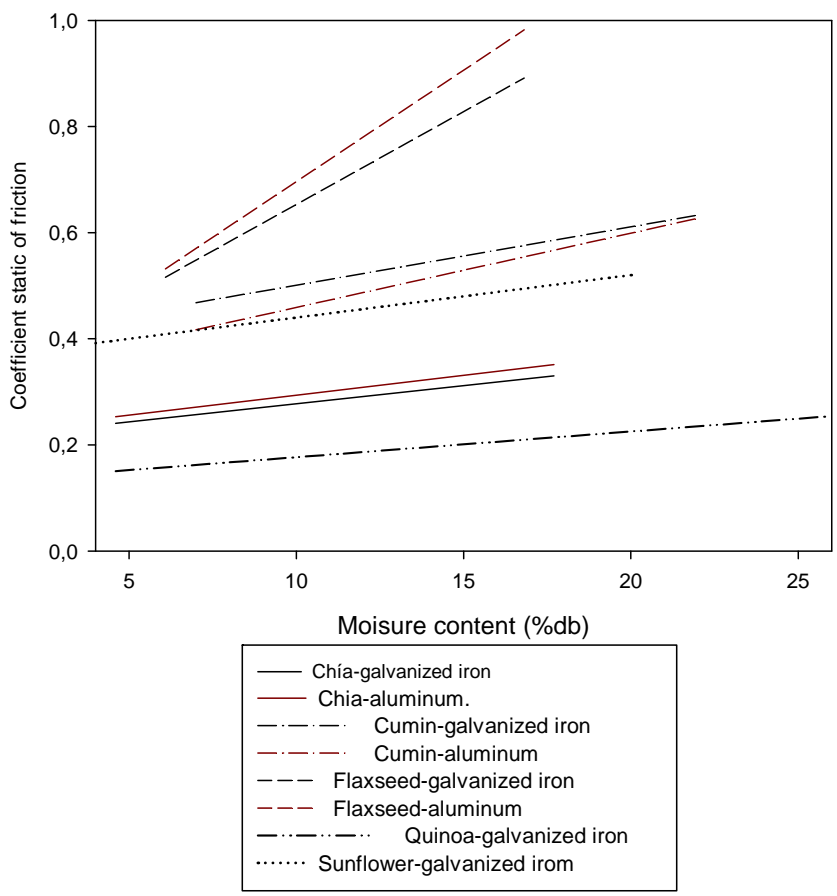

Figure 7. Effect of moisture content ( $x, \%$ d.b.) on coefficient of static friction. Dates correspond to the adjusted function reported by () [25], () [13], () [27], () [22] and () [15].

\section{Conclusions}

The engineering properties of dark chia seeds were evaluated as a function of the moisture content, in the range of $4.6 \%$ to $17.7 \%$ d.b. and their behavior was compared with amaranth, cumin, flaxseed, fenugreek, quinoa, rapeseed, safflower, soybean and sunflower. The principal dimensions of dark chia seed (length, width and thickness), geometric diameter, specific surface area, volume, equivalent diameter, and thousand seeds mass and static coefficient of friction on galvanized sheet and aluminium increased linearly as increasing the seed moisture content. Chia seed is one of the smallest (similar to amaranth and quinoa), and very light.

The sphericity did not present significant differences in the range of moisture content studied for dark chia seed. The most spherical seeds which were compared with chia seed ones were rapeseed, amaranth, soybean and quinoa. An increase in moisture content yields a de- 
crease in bulk and true density. The bulk density and porosity varied nonlinearly for chia seeds, showing a quadratic concave behavior as a function of moisture content.

The friction caused by the aluminum surface was slightly higher than that presented by the galvanized iron surface.

In general, the variation of the engineering properties of chia seed with the moisture content showed a similar trend to that reported for other seeds, with some exceptions. Nevertheless, they presented different variation ranges. It could be attributed to the seeds morphological and physiological characteristics.

The comparison of the data of the different seeds can be important for the design and adaptation of equipment for transporting, storage and processing.

\section{Acknowledgements}

This work was supported by a grant from Agencia Nacional de Promoción Científica y Tecnológica (ANPCyT); Argentina (PICT 2007-1085), Universidad Nacional de La Plata (UNLP) (11/X502), and Universidad Nacional del Centro de la Provincia de Buenos Aires (UNCPBA). E.N. Guiotto is recipient of a doctoral fellowship from the Consejo Nacional de Investigaciones Científicas y Técnicas (CONICET) and Agencia Nacional de Promoción Científica y Tecnológica (ANPCyT); V.Y. Ixtaina and M.C. Tomás are members of the career of Scientific and Technological Researcher of Consejo Nacional de Investigaciones Científicas y Técnicas (CONICET), Argentina; and S.M. Nolasco is a research scientist of Universidad Nacional del Centro de la Provincia de Buenos Aires (UNCPBA), Argentina.

\section{Nomenclature}

$D_{e}$ Equivalent Diameter (mm)

$D_{g}$ Geometric Diameter (mm)

d.b. dry basis

$L$ Length of seed (mm)

$m$ Unit mass of the seed (g)

$S$ Specific Surface area $\left(\mathrm{mm}^{2}\right)$

$T$ Thickness (mm)

$V$ Seed Volume $\left(\mathrm{mm}^{3}\right)$

$W$ Width of seed (mm)

$W_{1000}$ Thousand seed weight (g) 
x Moisture content (\% d.b.)

$\alpha$ Angle of tilt, degree

$\varepsilon$ Porosity of seed (\%)

$\phi$ Sphericity of seed

$\mu$ Static coefficient of friction, dimensionless

$\rho_{b}$ Bulk Density $\left(\mathrm{g} \mathrm{cm}^{-3}\right)$

$\rho_{r}$ True Density $\left(\mathrm{g} \mathrm{cm}^{-3}\right)$

\section{Author details}

Estefanía N. Guiotto ${ }^{1,2}$, Vanesa Y. Ixtaina ${ }^{1,2}$, Mabel C. Tomás² and Susana M. Nolasco ${ }^{1}$

*Address all correspondence to: mabtom@hotmail.com

*Address all correspondence to: snolasco@fio.unicen.edu.ar

1 Grupo de Investigaciones TECSE. Departamento de Ingeniería Química. Facultad de Ingeniería, UNCPBA, Olavarría, Buenos Aires, Argentina

2 Centro de Investigación y Desarrollo en Criotecnología de Alimentos (CIDCA), (CCT La Plata -CONICET) Facultad de Ciencias Exactas, UNLP, La Plata, Buenos Aires, Argentina

\section{References}

[1] Álvarez-Chávez, L. M., Valdivia-López, M. A., Alberto-Juárez, M. L., \& Tecante, A. (2008). Chemical characterization of the lipid fraction of mexican chia seed (Salvia hispanica L.). Int. J. Food Prop., 11, 687-697.

[2] Cahill, J. 2003. Ethnobotany of chia, Salvia hispanica L. (Lamiaceae). Econ. Bot. 57(4): 604-618.

[3] Palma, F., Donde, M., Lloyd, W.R., 1947. Fixed oils of Mexico. Part 1. Oil of chia- Salvia hispanica. J. Am. Oil Chem. Soc. 24, 27.

[4] Ayerza Jr., R., 1995. Oil Content and fatty acid composition of Chia (Salvia hispanica L.) from five northwestern locations in Argentina. J. Am. Oil Chem. Soc. 72, 10791081.

[5] Bushway, A.A., Belyea, P.R., Bushway, R.J., 1981. Chia seed as asource of oil, polysaccharide, and protein. J. Food Sci. 46, 1349-1350. 
[6] Capitani, M.I.; Spotorno, V.; Nolasco S.M.; Tomás, M.C. (2012). Physicochemical and functional characterization of by-products from chia (Salvia hispanica L.) seeds of Argentina LWT - Food Sci. Technol. 45, 94-102.

[7] Coates, W., \& Ayerza, R. (1996). Production potencial of chia in northwestern Argentina. Ind. Crops and Prod., 5, 229-233.

[8] Ixtaina, V.Y., Martínez, M.L., Spotorno, V., Mateo, C.M., Maestri, D.M., Diehl, B.W., (2011). Characterization of chia seed oils obtained by pressing and solvent extraction. J. Food Comp. Anal., 24, 166-174.

[9] Ixtaina, V. Y., M. I. Capitani, S. M. Nolasco, and M. C. Tomás. 2010. Caracterización microestructural de la semilla y el mucílago de chia (Salvia hispanica L.). In Proc. XXVIII Congreso Argentino de Química. Buenos Aires, Argentina: Asociación Química Argentina.

[10] Commission of the European Communities. 2009. Commission Regulation (EC) 827/2009. Official J. European Union 52: 12-13.

[11] Brann, M. 2008. Chia: The Ord Valley's new super crop. ABC Rural. Sydney, Australia: Australian Broadcasting Corporation. Available at: www.abc.net.au/rural/content/ 2008/s2367335.htm. Accessed 12 July 2010.

[12] Ixtaina, V. Y., S. M. Nolasco, and M. C. Tomas. 2008. Physical properties of chia (Salvia hispanica L.) seeds. Ind. Crops Prod. 28(3): 286-293.

[13] Singh, K. K., and T. K. Goswami. 1996. Physical properties of cumin seed. J. Agric. Eng. Res. 64(2): 93-98.

[14] ASAE Standards. 1999. S352.2: Moisture measurement: Unground grain and seeds. St. Joseph, Mich.: ASAE.

[15] Gupta, R. K., and S. K. Das. 1997. Physical properties of sunflower seeds. J. Agric. Eng. Res. 66(1): 1-8.

[16] Altuntaş, E., E. Özgöz, and Ö. F. Taşer. 2005. Some physical properties of fenugreek (Trigonella foenum-graceum L.) seeds. J. Food Eng. 71(1): 37-43.

[17] Baümler, E., A. Cuniberti, S. M. Nolasco, and I. C. Riccobene. 2006. Moisture-dependent physical and compression properties of safflower seed. J. Food Eng. 72(2): 134-140.

[18] A.K. de Figueiredo, E. Baümler, I.C. Riccobene, S.M. Nolasco Moisture-dependent engineering properties of sunflower seeds with different structural characteristics J. Food Eng. 102 (2011) 58-65.

[19] Thompson, R. A., and G. W. Isaacs. 1967. Porosity determination of grains and seeds with air comparison pycnometer. Trans. ASAE 10(5): 693-696.

[20] Mohsenin, N. N. 1970. Physical Properties of Plant and Animal Materials. New York, N.Y.: Gordon and Breach Science 
[21] Özarslan, C. 2002. Physical properties of cotton seed. Biosyst. Eng. 83(2): 169-174.

[22] Vilche, C., M. Gely, and E. Santalla. 2003. Physical properties of quinoa seeds. Biosyst. Eng. 86(1): 59-65.

[23] Deshpande, S. D., S. Bal, and T. P. Ojha. 1993. Physical properties of soybean. J. Agric. Eng. Res. 56(2): 89-98.

[24] Abalone, R., A. Cassinera, A. Gastón, and M. A. Lara. 2004. Some physical properties of amaranth seeds. Biosyst. Eng. 89(1): 109-117.

[25] Guiotto, E., Ixtaina, V.Y., Tomás, M. C. and Nolasco, S.M. 2011. Influence of moisture content on physical properties of chia (Salvia hispanica L.) seeds, Trans.ASABE 54 (2): 527-533.

[26] Omobuwajo, T.O., Sanni, L.A., Balami, Y.A. 2000. Physical properties of sorrel (Hibiscus sabdariffa) seeds. J. Food Eng. 45, 37-41.

[27] Coşkuner, Y., and E. Karababa. 2007. Some physical properties of flaxseed (Linum usitatissimum L.). J. Food Eng. 78: 1067-1073.

[28] Çalişir, S., T. Marakoğlu, H. Öğüt, and Ö. Öztürk. 2005. Physical properties of rapeseed (Brassica napus oleifera L.). J. Food Eng. 69(1): 61-66.

[29] Baryeh, E. A. 2002. Physical properties of millet. Baryeh, E. A. 2002. Physical properties of millet. J. Food Eng., 51, 39-46. 
